\title{
PENGARUH PEMBERIAN IBA (Indole Butyric Acid) DAN KONSENTRASI NAA (Naphthalene Acetic Acid) TERHADAP KEBERHASILAN PENYETEKAN SIRIH MERAH (Piper crocatum Ruiz and Pav.)
}

\author{
Desi Maulida, Rugayah \& Tri Dewi Andalasari \\ Jurusan Agroteknologi, Fakultas Pertanian Universitas Lampung \\ Jl.Prof. Soemantri Bradjonegoro, No. 1, Bandar Lampung 35145 \\ E-mail:desi@polinela.ac.id
}

\begin{abstract}
The research was conducted at the cutting red bettle (Piper crocatum Ruiz and Pav.) to determined the effect of (1) the difference growth of cuttings of red bettle which are given IBA and without IBA, (2) the concentration of NAA on growth of cutting red bettle, (3) the concentration of NAA on growth of cutting red bettle on each given IBA. The treatment was arranged in factorial $(2 \times 4)$ in randomized block design with three replication. The first factor were without IBA $\left(\mathrm{A}_{0}\right)$ and the given of $1000 \mathrm{ppm}$ IBA $\left(\mathrm{A}_{1}\right)$. The second factor were the concentration of NAA consists of: $0 \mathrm{ppm}\left(\mathrm{B}_{0}\right), 1000 \mathrm{ppm}(\mathrm{B} 1), 2000$ $\mathrm{ppm}\left(\mathrm{B}_{2}\right)$, and $4000 \mathrm{ppm}\left(\mathrm{B}_{3}\right)$. The results showed that the NAA concentration of $4000 \mathrm{ppm}$ produced the most number of roots on either at the node or at the base of cutting. Planting cutting red bettle which given IBA $1000 \mathrm{ppm}$ was able to accelerated the time leaves open and increased the number of cutting which germinate. The mixtured of giving IBA $1000 \mathrm{ppm}$ and the concentration of NAA $4000 \mathrm{ppm}$, produced the most number of cutting that germinated.
\end{abstract}

Key Word : red bettle, given IBA, concentration NAA

\section{PENDAHULUAN}

Tanaman sirih merah (Piper crocatum Ruiz and $P a v)$ termasuk dalam famili piperaceae, memiliki multifungsi sebagai tanaman obat dan tanaman hias. Potensi sirih merah sebagai tanaman obat multifungsi sangat besar sehingga perlu ditingkatkan dalam penggunaannya sebagai bahan obat modern. Dalam daun sirih merah terkandung senyawa fitokimia yakni alkoloid, saponin, tanin dan flavonoid. Secara empiris sirih merah dapat menyembuhkan berbagai jenis penyakit seperti diabetes militus, hepatitis, batu ginjal, menurunkan kolesterol, mencegah stroke, asam urat, hipertensi, radang liver, radang prostat, radang mata, keputihan, maag, kelelahan, nyeri sendi dan memperhalus kulit (Sudewo, 2005).

Sebagai tanaman multifungsi, perkembangan sirih merah mempunyai prospek cukup cerah sehingga akan dibutuhkan bahan tanam dalam jumlah banyak, salah satunya dengan perbanyakan secara vegetatif. Perbanyakan tanaman sirih merah secara vegetatif dapat dilakukan dengan beberapa cara yakni setek, cangkok, dan perundukan. Setek merupakan cara perbanyakan yang paling praktis, namun menurut Sudewo (2005) keberhasilannya berkisar antara 40-70\%.

Untuk meningkatkan keberhasilan penyetekan, perlu dicoba penggunaan zat pengatur tumbuh (ZPT).
Jenis ZPT yang sering digunakan pada setek ialah golongan auksin, diantaranya indole butyric acid (IBA) dan napthtalene acetic acid (NAA) (Wattimena, 1988). Hasil penelitian Husada (2008) menunjukkan bahwa NAA dan IBA yang diberikan setek sirih merah dapat mempercepat keluarnya akar sehingga umur setek untuk pindah tanam lebih cepat dan pada media baru setek lebih cepat menyesuaikan diri. Setek yang telah berakar akan lebih cepat menumbuhkan tunas. Hal ini sesuai dengan pernyataan Heddy (1986) bahwa, NAA dan IBA terbukti efektif sebagai perangsang akar.

Penelitian ini bertujuan untuk mengetahui perbedaan pertumbuhan setek sirih merah yang diberi IBA dan tanpa IBA, mengetahui konsentrasi NAA yang menghasilkan pertumbuhan setek sirih merah yang terbaik, dan mengetahui pengaruh pemberian IBA pada pertumbuhan setek tanaman sirih merah pada masingmasing konsentrasi NAA yang digunakan.

\section{BAHAN DAN METODE}

Penelitian dilaksanakan di lingkungan Politeknik Negeri Lampung, mulai awal Juli sampai September 2010. Bahan yang digunakan adalah bibit tanaman sirih merah umur \pm 7 bulan, formulasi bubuk NAA dengan kosentrasi 0, 1000, 2000, dan 4000 ppm; formulasi bubuk IBA dengan konsentrasi 0 dan1000 ppm, pasir malang, 
arang sekam, talk, larutan $0,1 \mathrm{NaOH}$, dan fungisida Banlate. Rancangan yang digunakan dalam penelitian ini adalah rancangan kelompok teracak sempurna dengan 3 (tiga) ulangan. Rancangan perlakuan disusun secara faktorial $(2 \times 4)$, dengan faktor pertama adalah pemberian IBA yaitu tanpa IBA $\left(\mathrm{A}_{0}\right)$ dan IBA konsentrasi $1000 \mathrm{ppm}\left(\mathrm{A}_{1}\right)$. Faktor yang kedua adalah konsentrasi NAA yang terdiri dari: $0 \mathrm{ppm}\left(\mathrm{B}_{0}\right), 1000$ ppm ( $\left.\mathrm{B}_{1}\right), 2000 \mathrm{ppm}\left(\mathrm{B}_{2}\right)$, dan $4000 \mathrm{ppm}\left(\mathrm{B}_{3}\right)$. Total kombinasi perlakuan sebanyak 8 dan setiap kombinasi perlakuan diulang tiga kali. Masing-masing pot ditanam 5 setek untuk pengamatan 35 hari. Homogenitas ragam diuji dengan uji Bartlett dan kemenambahan data diuji dengan uji Tukey. Jika asumsi terpenuhi maka data dianalisis ragam, kemudian dilanjutkan dengan pemisahan nilai tengah dengan BNT pada taraf 5\%. Kombinasi perlakuan antara campuran IBA dan NAA adalah sebagai berikut:

1. Tanpa pemberian ZPT (hanya bubuk talk dan banlate) $\left(a_{0} b_{0}\right)$

2. Tanpa pemberian IBA dan 1000 ppm NAA $\left(\mathrm{A}_{0} \mathrm{~B}_{1}\right)$

3. Tanpa pemberian IBA dan 2000 ppm NAA $\left(\mathrm{A}_{0} \mathrm{~B}_{2}\right)$

4. Tanpa pemberian IBA dan 4000 ppm NAA $\left(\mathrm{A}_{0} \mathrm{~B}_{3}\right)$

5. Pemberian 1000 ppm IBA dan tanpa NAA $\left(\mathrm{A}_{1} \mathrm{~B}_{0}\right)$

6. Pemberian 1000 ppm IBA dan 1000 ppm NAA $\left(\mathrm{A}_{1} \mathrm{~B}_{1}\right)$

7. Pemberian 1000 ppm IBA dan 2000 ppm NAA $\left(\mathrm{A}_{1} \mathrm{~B}_{2}\right)$

8. Pemberian 1000 ppm IBA dan 4000 ppm NAA $\left(\mathrm{A}_{1} \mathrm{~B}_{3}\right)$

Jumlah Banlate, talk, bubuk IBA, dan bubuk NAA yang dibutuhkan untuk pembuatan pada masing-masing perlakuan campuran IBA dan NAA dapat dilihat pada Tabel 1.

Pengamatan yang dilakukan pada saat tanaman berumur 35 hari sejak penyetekan adalah persentase setek hidup, waktu muncul tunas, waktu membuka daun, jumlah akar pada buku, jumlah akar pada pangkal setek, panjang akar terpanjang pada buku, panjang akar terpanjang pada pangkal setek, dan penampakan akar.

\section{HASIL DAN PEMBAHASAN}

Hasil pengamatan umur 35 hari setelah penyetekan menunjukkan bahwa; 1) terdapat pengaruh pemberian IBA terhadap waktu membuka daun, jumlah setek yang bertunas, dan jumlah akar pada pangkal setek tetapi tidak berpengaruh pada waktu muncul tunas, jumlah akar pada buku, panjang akar terpanjang pada buku dan panjang akar terpanjang, 2) terdapat pengaruh konsentrasi NAA pada jumlah akar pada baik pada buku maupun pangkal setek tetapi tidak berpengaruh pada waktu muncul tunas, waktu membuka daun, jumlah setek yang bertunas, panjang akar terpanjang pada buku, dan panjang akar terpanjang pada setek, 3) ada ketergantungan pengaruh konsentrasi NAA dengan pemberian IBA yaitu pada jumlah setek bertunas dan jumlah akar pada buku. Hasil rata-rata pengamatan pada waktu muncul tunas, panjang akar terpanjang pada buku dan pangkal setek sirih merah umur 35 hari setelah penyetekan disajikan pada Tabel 2.

Hasil penelitian menunjukan bahwa pada perlakuan tanpa pemberian IBA membutuhkan waktu membuka daun lebih cepat yaitu 9,13 hari, berbeda dengan perlakuan pemberian IBA yang membutuhkan waktu 9,88 hari untuk membuka daun (Gambar 1).

Hasil penelitian menunjukkan bahwa pada umur setek 35 hari pemberian IBA berpengaruh pada peningkatan jumlah setek yang bertunas dan ada ketergantungan antara pemberian IBA dengan konsentrasi NAA dalam meningkatkan jumlah setek yang bertunas. Pada perlakuan pemberian NAA yang disertai dengan pemberian IBA 1000 ppm akan meningkatkan jumlah setek yang bertunas. Jumlah setek

Tabel 1. Pembuatan konsentrasi campuran antara IBA dan NAA

\begin{tabular}{cccccc}
\hline $\begin{array}{c}\text { Perlakuan konsentrasi } \\
\text { IBA + NAA }(\mathrm{ppm})\end{array}$ & $\begin{array}{c}\text { Jumlah IBA } \\
(\mathrm{g})\end{array}$ & $\begin{array}{c}\text { Jumlah NAA } \\
(\mathrm{g})\end{array}$ & $\begin{array}{c}\text { Banlate } 4 \% \\
(\mathrm{~g})\end{array}$ & $\begin{array}{c}\text { Talk } \\
(\mathrm{g})\end{array}$ & $\begin{array}{c}\text { Bobot total } \\
\text { campuran }(\mathrm{g})\end{array}$ \\
\hline $0+0$ & 0,00 & 0,00 & $0,2 / 0,2$ & $49,80 / 49,80$ & $50 / 50$ \\
$0+1000$ & 0,00 & 0,05 & $0,2 / 0,2$ & $49,80 / 49,75$ & $50 / 50$ \\
$0+2000$ & 0,00 & 0,1 & $0,2 / 0,2$ & $49,80 / 49,70$ & $50 / 50$ \\
$0+4000$ & 0,00 & 0,2 & $0,2 / 0,2$ & $49,80 / 49,60$ & $50 / 50$ \\
$1000+0$ & 0,05 & 0,00 & $0,2 / 0,2$ & $49,75 / 49,80$ & $50 / 50$ \\
$1000+1000$ & 0,05 & 0,05 & $0,2 / 0,2$ & $49,75 / 49,75$ & $50 / 50$ \\
$1000+2000$ & 0,05 & 0,1 & $0,2 / 0,2$ & $49,75 / 49,70$ & $50 / 50$ \\
$1000+4000$ & 0,05 & 0,2 & $0,2 / 0,2$ & $49,75 / 49,60$ & $50 / 50$ \\
\hline
\end{tabular}


Tabel 2. Hasil rata-rata pengamatan pada waktu muncul tunas, panjang akar terpanjang pada buku dan pangkal setek sirih merah umur 35 hari setelah penyetekan

\begin{tabular}{cccc}
\hline \multirow{2}{*}{ Perlakuan (ppm) } & \multicolumn{3}{c}{ Variabel pengamatan } \\
\cline { 2 - 4 } & $\begin{array}{c}\text { Waktu muncul } \\
\text { tunas (hari) }\end{array}$ & $\begin{array}{c}\text { Panjang akar terpanjang } \\
\text { pada buku }(\mathrm{cm})\end{array}$ & $\begin{array}{c}\text { Panjang akar terpanjang pada } \\
\text { pangkal setek }(\mathrm{cm})\end{array}$ \\
\hline Tanpa IBA : 0 & & & $2,56 \mathrm{a}$ \\
\hline 0 NAA & $30,50 \mathrm{a}$ & $3,15 \mathrm{a}$ & $3,04 \mathrm{a}$ \\
1000 NAA & $32,50 \mathrm{a}$ & $3,78 \mathrm{a}$ & $3,03 \mathrm{a}$ \\
2000 NAA & $31,40 \mathrm{a}$ & $3,51 \mathrm{a}$ & $3,34 \mathrm{a}$ \\
4000 NAA & $31,73 \mathrm{a}$ & $3,75 \mathrm{a}$ & $2,83 \mathrm{a}$ \\
\hline Dengan IBA : 1000 & & & $2,85 \mathrm{a}$ \\
\hline 0 NAA & $32,47 \mathrm{a}$ & $2,67 \mathrm{a}$ & $3,33 \mathrm{a}$ \\
1000 NAA & $31,40 \mathrm{a}$ & $3,47 \mathrm{a}$ & $3,47 \mathrm{a}$ \\
2000 NAA & $32,07 \mathrm{a}$ & $3,03 \mathrm{a}$ & 3,09 \\
4000 NAA & $31,97 \mathrm{a}$ & $3,54 \mathrm{a}$ & 3,36 \\
\hline Rata-rata & 31,75 & &
\end{tabular}

Keterangan: Nilai tengah sekolom yang diikuti huruf yang sama tidak berbeda nyata berdasarkan Uji BNT pada $\alpha=0,05$.

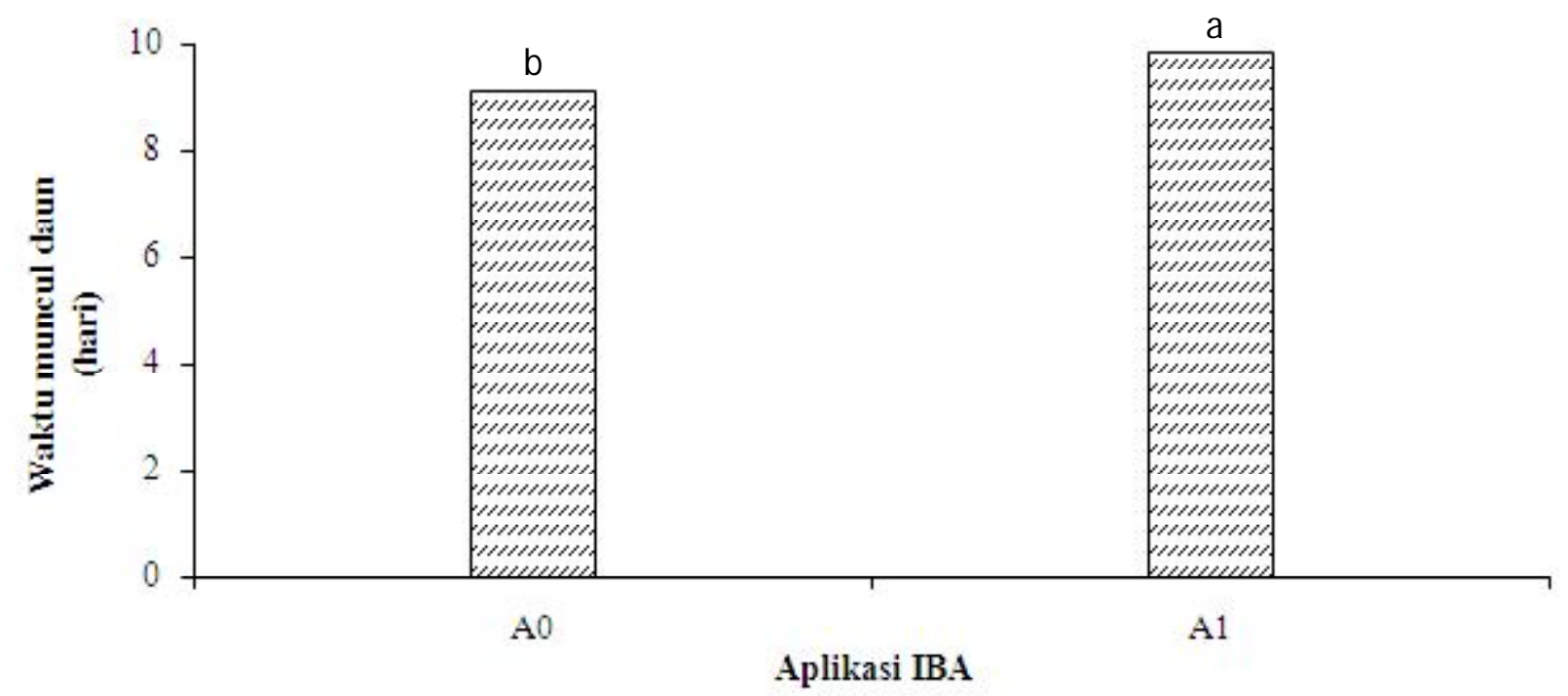

Gambar 1. Pengaruh pemberian IBA terhadap waktu membuka daun pada setek tanaman sirih merah umur 35 hari. Bar dengan huruf yang sama diatasnya menunjukkan tidak berbeda nyata berdasarkan uji BNT pada $\alpha=0,05$. Nilai $B N T=0,67$.

bertunas paling banyak yaitu 2 tunas didapatkan pada perlakuan NAA 4000 ppm dan IBA 1000 ppm (Gambar 2).

Hasil penelitian menunjukkan bahwa pada umur setek 35 hari pemberian NAA mampu meningkatkan jumlah akar pada buku. Pada perlakuan pemberian NAA sebaiknya tidak disertai dengan pemberian IBA 1000 ppm untuk meningkatkan jumlah akar pada buku. Jumlah akar pada buku paling banyak yaitu 4 helai didapatkan pada perlakuan NAA 4000 ppm dan tanpa IBA (Gambar 3).

Hasil penelitian menunjukkan bahwa pemberian IBA dan konsentrasi NAA berpengaruh pada jumlah akar pada pangkal setek sirih merah. Setek tanpa pemberian IBA menghasilkan jumlah akar pada pangkal setek lebih banyak yaitu 3,44 helai, dibandingkan dengan 


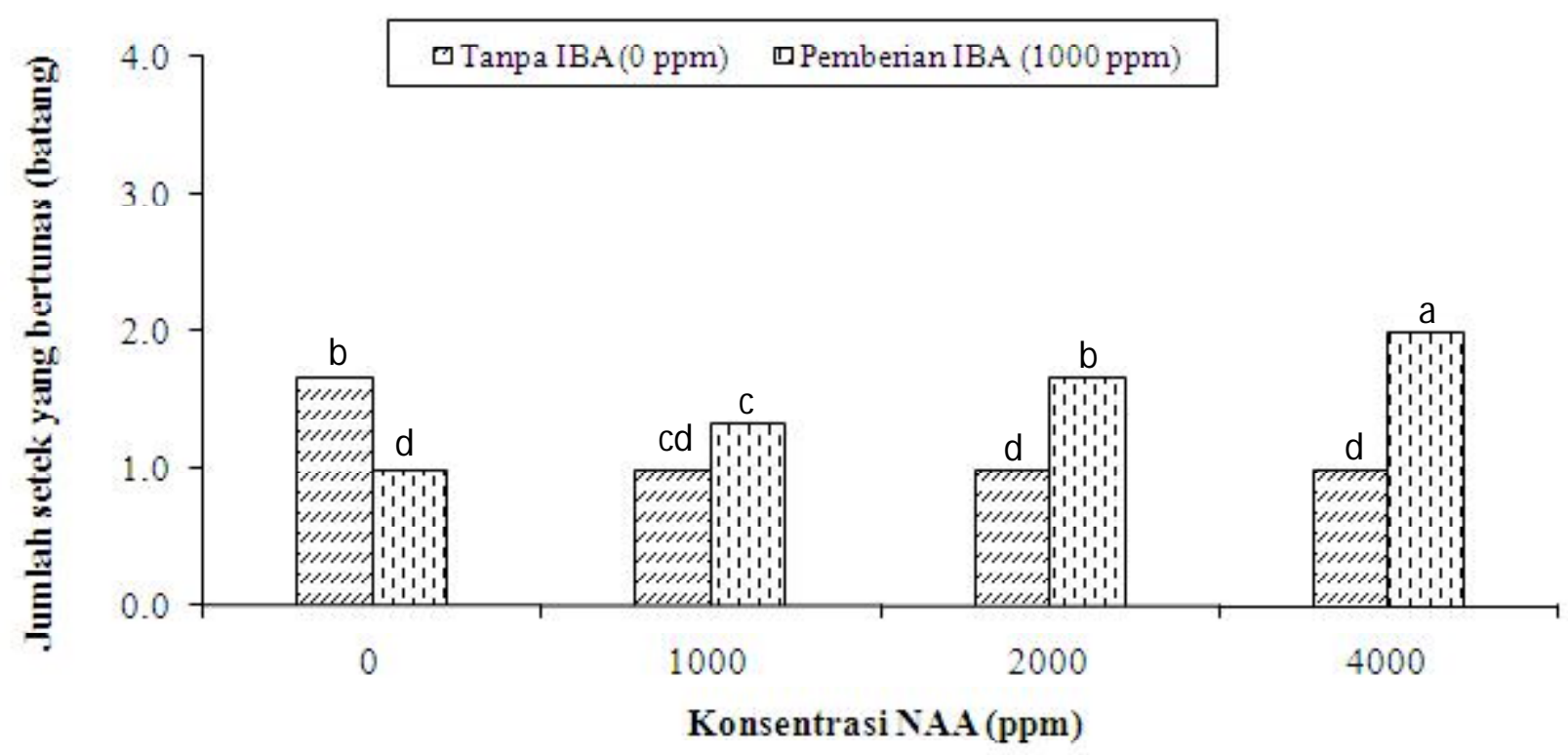

Gambar 2. Rata-rata jumlah setek yang bertunas pada berbagai konsentrasi NAA dengan IBA atau tanpa IBA umur 35 hari. Bar dengan huruf yang sama diatasnya menunjukkan tidak berbeda nyata berdasarkan uji BNT pada $\alpha=0,05$. Nilai $B N T=0,23$.

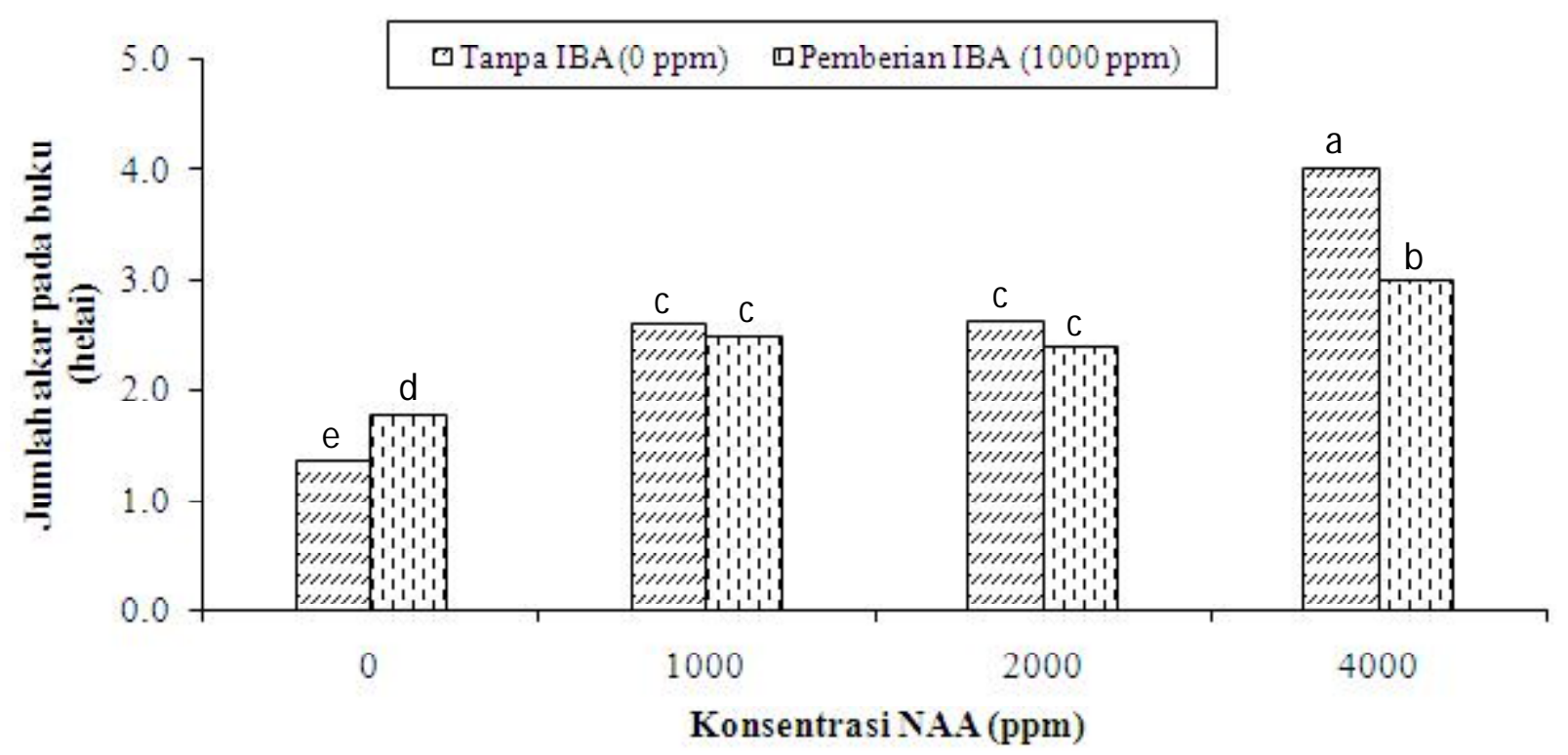

Gambar 3. Rata-rata jumlah akar pada buku pada berbagai konsentrasi NAA dengan IBA atau tanpa IBA umur 35 hari. Bar dengan huruf yang sama diatasnya menunjukkan tidak berbeda nyata berdasarkan uji BNT pada $\alpha=0,05$. Nilai $B N T=0,23$.

pemberian IBA1000 ppm yang hanya menghasilkan jumlah akar pada pangkal setek sebanyak 2,33 helai (Gambar 4).

Pemberian NAA 4000 ppm menghasilkan jumlah akar pada pangkal setek paling banyak yaitu 3,55 helai, berbeda dengan perlakuan konsentrasi NAA 2000 ppm yang hanya menghasilkan 3,01 helai. Pemberian NAA konsentrasi 2000 ppm tidak berbeda dengan 1000 ppm yang menghasilkan jumlah akar 2,62 helai, tetapi berbeda dengan perlakuan tanpa NAA yang menghasilkan jumlah akar pada pangkal setek paling sedikit yaitu 2,37 helai (Gambar 5).

Keberhasilan penyetekan suatu tanaman ditentukan oleh terbentuknya akar. Menurut Dawson and King (1994), faktor yang menentukan keberhasilan pembentukan akar adalah kondisi fisiologis tanaman 


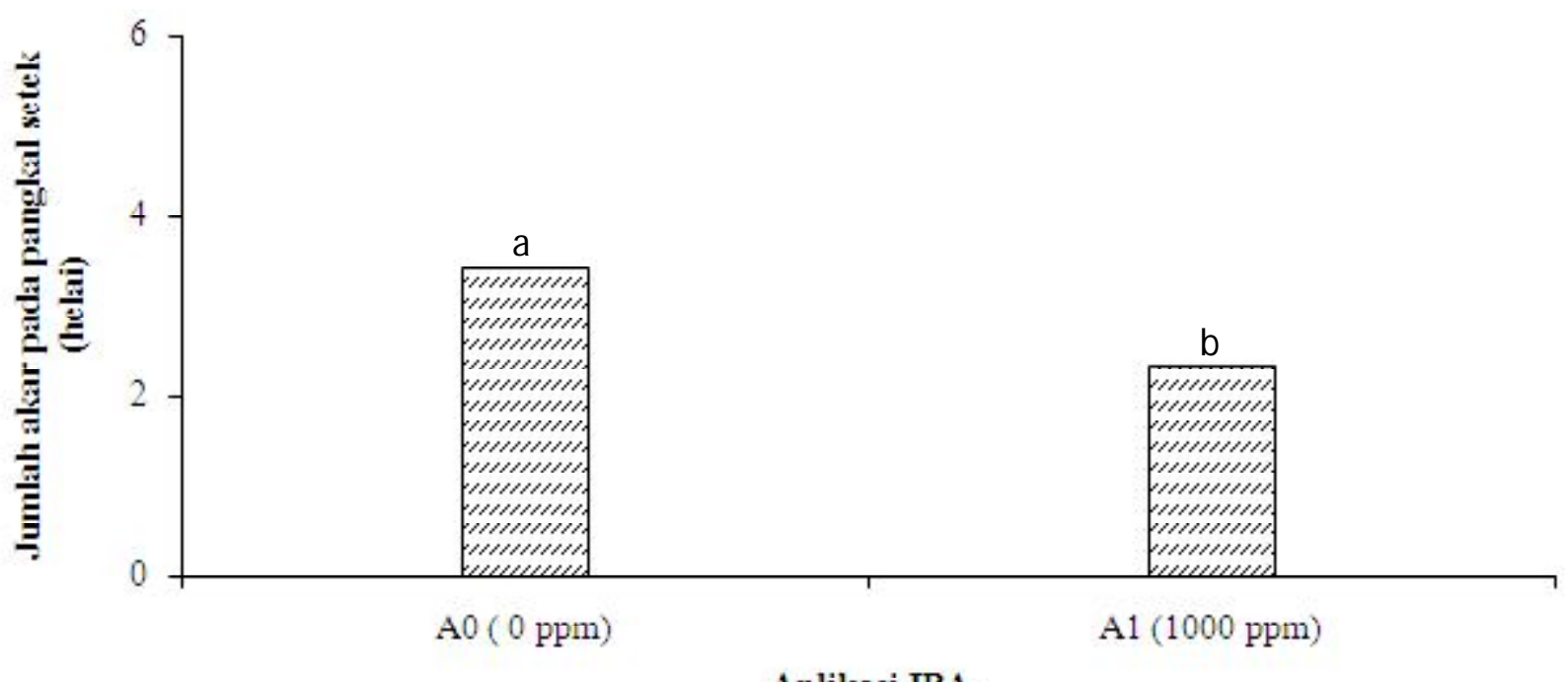

Aplikasi IBA

Gambar 4. Pengaruh pemberian IBA pada jumlah akar pada pangkal setek tanaman sirih merah umur 35 hari. Bar dengan huruf yang sama diatasnya menunjukkan tidak berbeda nyata berdasarkan uji BNT pada $\alpha=0,05$.Nilai BNT $5 \%=0,29$.

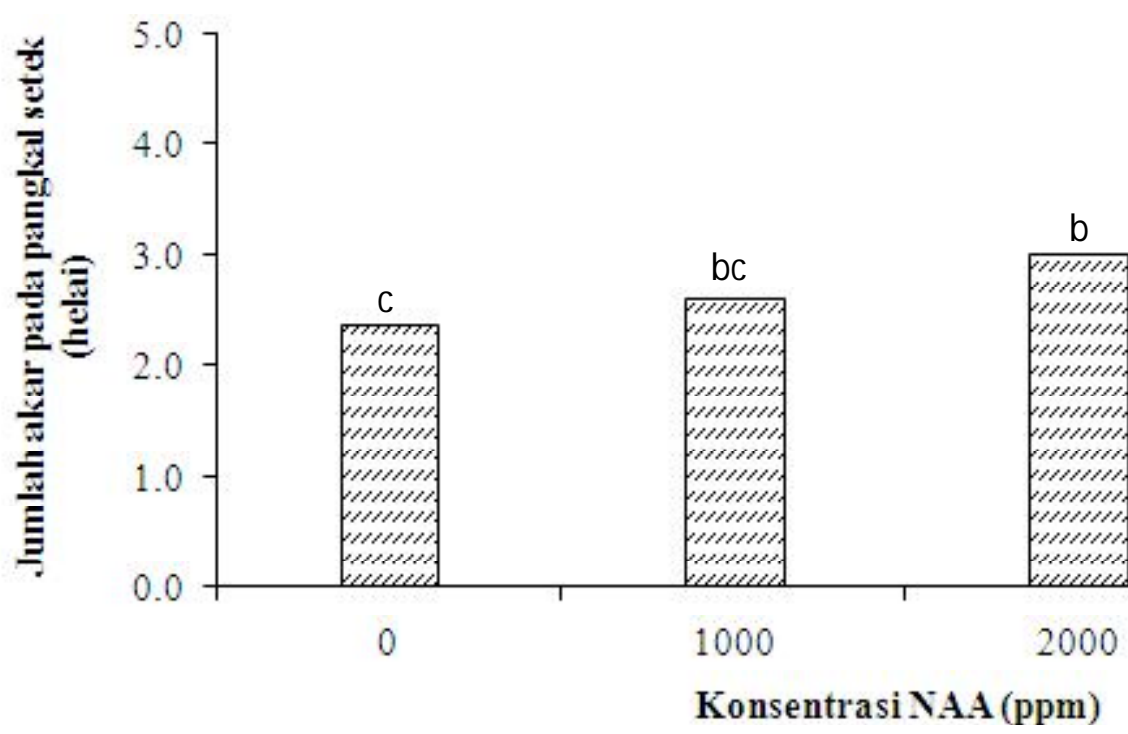

Gambar 5. Pengaruh konsentrasi NAA terhadap jumlah akar pada pangkal setek umur 35 hari. Bar dengan huruf yang sama diatasnya menunjukkan tidak berbeda nyata berdasarkan uji BNT pada $\alpha=0,05$.Nilai BNT $5 \%=0,41$.

induk (stock plant), umur tanaman induk, jenis bahan setek, waktu pengambilan stek, zat pengatur tumbuh (ZPT), adanya tunas dan daun, umur bahan stek, dan kondisi lingkungan. Salah satu faktor yang menentukan pembentukan akar adalah zat pengatur tumbuh dari golongan auksin (Hartmann et al., 1997). Auksin digunakan untuk pertumbuhan kalus, pemanjangan tunas dan pembentukan akar. Dalam konsentrasi rendah auksin akan memacu tunas adventif, sedangkan konsentrasi tinggi mendorong terbentuk kalus (Pierik, 1987). Pemilihan jenis auksin dan konsentrasinya ditentukan oleh tipe pertumbuhan dan level auksin endogen. Menurut Noggle dan Fritz (1993), pemberian IBA akan meningkatkan pemanjangan sel terutama ke arah vertikal sehingga akan meningkatkan panjang tunas.

Pembentukan akar pada setek dapat diukur berdasarkan jumlah dan panjang akar. Jumlah akar yang banyak dan panjang diharapkan akan memberikan pengaruh pada pertumbuhan tunas yang lebih baik, karena dengan sistem perakaran yang sempurna penyerapan unsur hara dan air akan lebih banyak sesuai dengan kebutuhan tanaman tersebut untuk mendukung 
metabolisme di dalam tanaman. Kriteria pertumbuhan setek yang baik ditentukan oleh kecepatan tumbuh tunas, membuka daun, jumlah daun, panjang ruas, dan bobot setek secara keseluruhan.

Pembentukan akar pada setek dikendalikan oleh sejumlah faktor yang saling berinteraksi baik dari dalam maupun luar tanaman yang peranannya sangat kompleks. Setek yang telah membentuk akar akan berpengaruh pada kemampuan untuk tumbuh dan membentuk tunas yang lebih tinggi. Jika ada salah satu faktor yang membatasi maka seluruh proses pembentukan akar mungkin akan terhambat (Economon dan Read, 1986 dalam Wuryaningsih, 2000). Lestari (2011) mengatakan bahwa jenis dan konsentrasi ZPT yang tepat untuk masing masing tanaman tidak sama karena tergantung pada genotipe serta kondisi fisiologi jaringan tanaman.

Hasil penelitian yang dilakukan pada setek sirih merah umur 35 hari menunjukkan bahwa, pemberian NAA 1000, 2000, dan 4000 ppm mampu meningkatkan jumlah akar baik pada buku maupun pangkal setek. Pada pemberian NAA 4000 ppm mampu menghasilkan jumlah akar pada pangkal setek paling banyak yaitu 3,55 helai, berbeda dengan perlakuan tanpa NAA yang menghasilkan jumlah akar pada pangkal setek paling sedikit yaitu 2,37 helai. Hal ini didukung oleh hasil penelitian Rudianto (2010) yang menunjukkan bahwa pemberian NAA 1000 ppm meningkatkan pada jumlah akar pada pangkal setek sirih merah.

Pada pengamatan jumlah akar pada buku, pemberian NAA 1000, 2000, dan 4000 ppm yang disertai dengan pemberian IBA 1000 ppm justru akan menurunkan jumlah akar yang terbentuk (jumlah akar pada buku lebih sedikit). Jumlah akar pada buku paling banyak yaitu 4 helai didapat pada perlakuan NAA 4000 ppm dan tanpa IBA, sedangkan paling sedikit yaitu 1,37 helai didapat pada perlakuan tanpa pemberian IBA dan NAA (perlakuan kontrol). Hal tersebut sejalan dengan hasil penelitian Husada (2008), yang menyatakan bahwa pemberian IBA konsentrasi 1000, 2000, dan 4000 ppm tidak berpengaruh terhadap jumlah akar adventif primer pada buku, tetapi pemberian NAA dari 1000 hingga 4000 ppm mampu meningkatkan jumlah akar adventif primer pada buku setek sirih merah. Hal tersebut didukung pula oleh pernyataan Rudianto (2010) bahwa, pemberian NAA 1000 ppm mampu meningkatkan jumlah akar pada buku setek sirih merah, sedangkan perlakuan IBA 1000, 2000, dan 4000 ppm tidak berpengaruh.

Pada perlakuan pemberian IBA 1000 ppm, tidak menunjukkan adanya pengaruh yang positif pada pembentukan akar, baik pada buku maupun pangkal setek. Bahkan pada pembentukan akar pada buku, dengan pemberian IBA 1000 ppm justru menurun, namun sebaliknya pemberian IBA 1000 ppm dapat meingkatkan pertumbuhan tunas yang ditunjukkan oleh meningkatnya jumlah setek yang bertunas. Pemberian IBA 1000 ppm yang disertai dengan NAA 1000, 2000, dan 4000 ppm mampu meningkatkan jumlah setek yang bertunas. Jumlah setek bertunas paling banyak yaitu 2 tunas didapatkan pada perlakuan NAA 4000 ppm dan IBA $1000 \mathrm{ppm}$. Hal ini didukung oleh penelitian Muhidin (2005) bahwa pemberian IBA 200 ppm dapat memacu pertumbuhan tunas stek Vanilla planifolia. Menurut Kusumo (1990), sifat-sifat yang menyebabkan pemakaian IBA lebih berhasil adalah sifat kimianya yang mantap dan memberikan pengaruh yang lama serta tetap berada di dekat tempat perlakuan IBA dan sedikit menyebar ke tunas untuk pertumbuhan tunas-tunas tersebut.

Walaupun dilihat secara agronomis selisih jumlah setek yang bertunas dengan perlakuan tanpa NAA dan tanpa pemberian IBA 1000 ppm hanya 0,33, namun berdasarkan perhitungan secara ekonomi masih menguntungkan. Jika selisih 1 setek, keberhasilan setek yang bertunas 0,33 maka di dapat keuntungan dalam 100 setek Rp.60.000,00, sementara penambahan biaya untuk NAA dan IBA untuk 100 setek hanya Rp.1.700,00

\section{KESIMPULAN}

Berdasarkan hasil penelitian disimpulkan bahwa pengaruh pemberian IBA 1000 ppm hanya mampu meningkatkan jumlah setek yang bertunas, sedangkan tanpa penambahan IBA justru meningkatkan jumlah akar pada pangkal setek. Pemberian NAA konsentrasi 1000, 2000, dan 4000 ppm mampu meningkatkan jumlah akar baik pada buku maupun pada pangkal setek dibandingkan tanpa pemberian NAA. Pada pemberian NAA 4000 ppm bila diberi IBA 1000 ppm akan menghasilkan setek bertunas paling banyak dibandingkan dengan tanpa IBA dan NAA, tetapi untuk jumlah akar pada buku pemberian NAA yang disertai dengan pemberian IBA 1000 ppm justru menurun.

\section{SANWACANA}

Ucapan terima kasih disampaikan kepada Ir. Sri Ramadiana, M.Si. selaku penguji yang telah memberikan masukan dalam penyempurnaan dalam tulisan ini. 


\section{DAFTAR PUSTAKA}

Dawson. I. A. and R. W. King. 1994. Propagation of some woody Australian plants from cuttings. Australian Journal of Experimental Agriculture 34:1225-1231.

Hartmann, H. T., D. E. Kester, and F. T. Davies, JR. 1997. Plant Propagation Principle and Practise. Sixth Edition. Prentice Hall International Inc. New Jersey.

Heddy, S. 1986. Homon Tumbuhan. CV. Rajawali. Jakarta.

Husada, R. 2008. Pengaruh Beberapa Konsentrasi Napthalene Acetic Acid (NAA) atau Indole Butyric Acid (IBA) Pada Pembentukan Akar Adventif Setek Sirih Merah (Piper crocatum Ruiz and Pav.). Skripsi. Fakultas Pertanian. Universitas Lampung.

Kusumo, S. 1990. Zat Pengatur Tumbuh Tanaman. Penerbit CV. Yasaguna. Jakarta.

Lestari, E. G. 2011. Peranan Zat Pengatur Tumbuh Dalam Perbanyakan Tanaman Melalui Kultur Jaringan. Balai Besar Penelitian dan Pengembangan Bioteknologi dan Sumberdaya Genetik Pertanian. Bogor. Jurnal AgroBiogen 7 (1):63-68.
Muhidin. 2005. Efektivitas Komposisi IBA dan NAA terhadap Pertumbuhan Setek Batang Tanaman Panili (Vanilla planifolia Andrews). Tropika 13 (1): 80-86.

Noggle, G.R and G. J. Fritz. 1993. Introductory Plant Physiology. Second Edition. Penerjemah B. Sumantri. Gramedia Pustaka Utama. Jakarta.

Pierik, R. L. M. 1987. In Vitro Culture of Higher Plants. Martinus Nijhoff Publishers Dordrecht. Nederlands

Rudianto. 2010. Pengaruh Pemberian Napthalene Acetic Acid (NAA) dan konsentrasi Indole Butyric Acid (IBA) Terhadap Keberhasilan Penyetekan Sirih Merah (Piper crocatum Ruiz and Pav.). Skripsi. Fakultas Pertanian. Universitas Lampung.

Sudewo, B. 2005. Basmi Penyakit Dengan Sirih Merah. Agromedia Pustaka. Jakarta.

Wattimena, G. A. 1988. Zat Pengatur Tumbuh Tanaman. Institut Pertanian Bogor. Bogor.

Wuryaningsih. S. Satsiyati dan S. Andyantoro. 2000. Pengaruh Kultivar IBA dan Bahan Setek pada Perbanyakan Melati. Jurnal Agrotropika (2): 2630. 